\title{
Graphene Oxide and Derivatives: The Place in Graphene Family
}

\author{
Artur T. Dideikin and Alexander Y. Vul"* \\ Division of Solid State Electronics, loffe Institute, St. Petersburg, Russia
}

Graphene oxide (GO) is useful and promising material for graphene based applications in electronic, optics, chemistry, energy storage, and biology. At the beginning of graphene history GO was only a simple and cheap step for preparation of single and multilayer graphene films and bulk structures by reduction. The further studies revealed the substantial structure imperfection of graphene oxide derived materials due to the defects in initial graphite and incompletion of reducing process. However, the results of recent research demonstrated a great amount of unique chemical, optical and electronic properties of graphene oxide that allow regarding it as independent nanomaterial possessing a large area of applications. In general, it represents the ultra-large organic molecule containing 2D carbon mesh. Unlike conventional graphene it provides wide range of chemical methods for attachment of various functional groups to its surface for control optical transparency, electrical and thermal conductance. Recently developed methods for preparation of graphene oxide derivatives saturated by carboxyl groups open the new attractive application areas in green technologies including energy storage and utilizing nuclear wastes. The goal of the review is to summarize the results of recent studies of graphene oxide, derivatives and reveal the most promising directions to focus the efforts of researchers.

Reviewed by:

Wenling Zhang,

University of Alberta, Canada Francesco Buonocore,

Italian National Agency for New Technologies, Energy and Sustainable Economic Development (ENEA), Italy

*Correspondence:

Alexander Y. Vul' alexandervul@mail.ioffe.ru

Specialty section: This article was submitted to

Condensed Matter Physics,

a section of the journal

Frontiers in Physics

Received: 28 September 2018 Accepted: 10 December 2018

Published: 28 January 2019

Citation:

Dideikin AT and Vul' AY (2019) Graphene Oxide and Derivatives: The

Place in Graphene Family.

Front. Phys. 6:149

doi: 10.3389/fphy.2018.00149

\section{INTRODUCTION}

For the beginning its worth answering question: What is graphene oxide? At first graphene oxide (GO) was regarded as result of chemical exfoliation and oxidizing of layered crystalline graphite (natural or artificial) [1]. Amazingly, at definite conditions of oxidizing graphite carbon atoms conserve integrity $2 \mathrm{D}$ structure of layers with oxygen-containing functional groups attached to both sides of carbon plane and to the edges [2]. However quite recent results demonstrated that the same structure could also be obtained using alternative (bottom up) method by hydrothermal treatment of glucose [3] or even by chemical vapor deposition (CVD) technique [4]. Therefore today it worth giving more general definition on the basis of its structure: single atom carbon layer with both surfaces modified by oxygen containing functional groups. Like any 2D carbon GO can have single layer or multilayer structure [5]. Carbon layers in multilayer GO are separated by functional groups bonded to each layer of carbon atoms. Although GO like graphene is two dimensional carbon material, its properties are extremely far from that of graphene. It does not absorb visible light, have very low electric conductance compared to that of graphene and demonstrates significantly higher chemical activity.

For the first time graphene oxide was synthesized by Benjamin Brody in 1859 much earlier than graphene was discovered [6]. He invented method of making the graphite oxide. It consisted in oxidation and exfoliation of natural crystalline graphite and undoubtedly gave a noticeable 
amount of single layer graphene oxide. Unfortunately, at that time nobody knew about graphene. Only after more than one and half century after "The rise of graphene [7]" the old invention was recollected as an efficient and cheap way of making the new interesting and promising material.

\section{TECHNOLOGY OF GRAPHENE OXIDE}

\section{Approaches for Synthesis of Graphene Oxide}

The most recent methods of making GO based on the noticeable ability of layered graphite for intercalation. It allows atoms of active metals and some types of oxidation agents to penetrate between flat carbon layers of crystalline graphite increasing interlayer distance and modifying surfaces of layers by chemically bonded functional groups. Finally, the action of suitable oxidation agents causes complete disassembling of graphitic crystal into separate carbon monolayers with chemically modified surface.

The known methods for preparation graphene oxide (by Brodie, Staudenmaier, Hoffman) include application of strong acids (nitric and/or sulfur) and potassium chlorate. The most popular Hummers-Offeman method uses a mixture of concentrated $\mathrm{H}_{2} \mathrm{SO}_{4}, \mathrm{NaNO}_{3}$, and $\mathrm{KMnO}_{4}$. It provides a good yield and requires less time than previous methods. The final product of GO synthesis (Figure 1A) is yellow colored aqueous suspension of GO particles [8].

The modern improvements for GO preparations are based on Hummers oxidation and exfoliation of graphite [9]. The detailed review of known methods of preparation GO by oxidation of graphite is given in Singh et al. [10].

It is important to note, that conditions of chemical oxidation of graphite usually requires small $(<10 \mu \mathrm{m})$ size of particles of the initial material. In order to complete chemical reactions the intensive stirring or even ultra-sonication is usually required. These factors make obtaining large sized GO flakes more difficult. For this reason the mean size of particles in commercially available GO does not exceed several microns.

However main properties of GO itself and especially, colligative properties of macroscopic structures formed by GO (like lamellar films) strongly depend upon the mean size of flakes. Therefore, increase of size of synthesized GO particles remains a challenge for technology. For the reason some recent researches propose the improvements of GO preparation method targeted to obtain large and ultra large sized GO platelets (LGO and ULGO) [11]. The idea of the method is to split GO preparation process into two stages: soft chemical exfoliation of initial graphite into graphene flakes in liquid media and subsequent oxidation of resulting product in mild conditions. In particular using the interaction of crystalline graphite, chromium trioxide and hydrogen peroxide allows obtaining effectively exfoliated graphite at room temperature [12]. The conditions of the process promote conserving the integrity of prepared graphene flakes. Subsequent oxidation of prepared large graphene flakes at reduced (relatively to usual Hummers method) concentration of potassium permanganate allows obtaining large area uniform
GO flakes (Figure 1B) avoiding formation of oxidation defects $[9,17]$.

\section{Structure and Composition}

Figure 1 illustrates forms and structure of GO. Structure of GO has been studied by broad variety of methods. The results obtained by solid state nuclear magnetic resonance (NMR) $[15,18,19]$, X-ray photoelectron spectroscopy (XPS), and Xray absorption near-edge spectroscopy (XANES) [14, 20-26], Fourier transform infrared spectroscopy (FTIR) [21, 26-28], and Raman spectroscopy [16, 24, 29] suggest that the best description of GO sheet structure is given by Lerf-Klinovski's model [15] updated by Gao et al. [14] (Figure 1D). This model represents each GO particle by the basal plane of $s p^{3}$ hybridized carbon atoms with chemically bonded hydroxyl and epoxy functional groups situated in close proximity to each other on both sides of the plane. Edges of basal plane are terminated by carboxyl groups five or six membered lactol (O-C-O) rings, ketone and ester of tertiary alcohol. It is important to note that the mean content of edge functionalities inversely depends on the size of GO particles.

Aberration corrected high resolution transmission electron microscopy (HRTEM) images [13] (scheme on Figure 1C) as well as results of nanocontact atomic force microscopy (NC-AFM) study (Figure 1E) [30] have demonstrated that GO particles always contain some pristine graphene domains. The content and size of domains related to conditions of exfoliation/oxidation process of GO preparation. Content of $s p^{3} \mathrm{C}$-O bond that induces structural distortion of basal plane revealed by electron energy loss spectroscopy (EELS) [31] is related to the conditions of making GO and structure of starting graphite.

Perforations in basal plane shown in (Figure 1C) also related to defects of initial graphite and conditions of GO synthesis. The perforations are also terminated by the same functional groups that attached to the edges of GO particles.

\section{Properties of Graphene Oxide}

Figure 2 illustrates physical properties of GO. GO particles are highly hydrophilic. They form stable aqueous dispersions in wide range of concentrations. They form stable dispersions in a number of organic solvents like ethylene glycol, dimethylformamide (DMF), n-methyl-2-pyrrolidone (NMP), tetrahydrofuran (THF) [34] owing to hydrogen bonding between hydroxyl groups on their surface and solvent interface [35]. This property allows making films on the variety of substrates even using simple drop-casting method. Thin films of GO exhibit a high optical transparency.

Figure 2A demonstrates optical absorbance spectra of GO film [36]. Due to $s p^{3}$ hybridization of the most part of carbon atoms it behaves like wide-band-gap insulator. Electric conductivity of GO is determined by domination of dielectric regions of $s p^{3}$ carbon atoms bonded to oxygen containing groups that separate the domains of pristine graphene from each other. As result the conductance becomes less than $10^{-10} \mathrm{~S} \mathrm{~cm}^{-1}$ [14]. Figure 2B shows dependence of resistance of thermally reduced GO vs. $s p^{2}$ carbon content. The vertical dashed line indicates the percolation threshold at $s p^{2}$ fraction of $\sim 0.6$. 
A

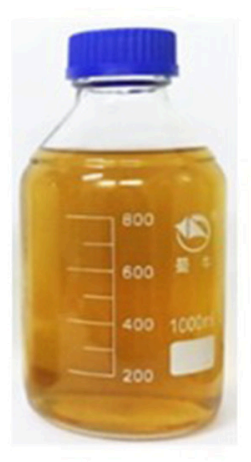

B

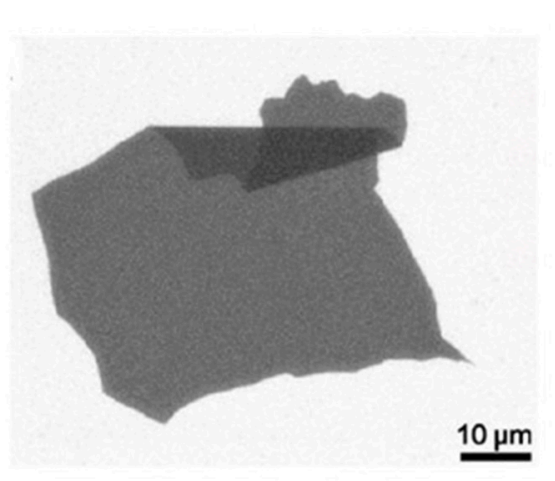

D

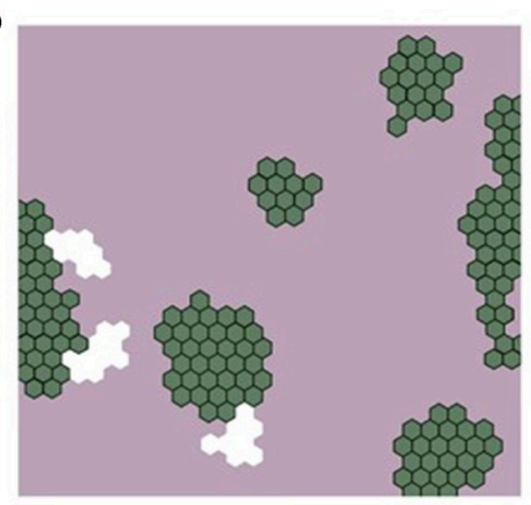

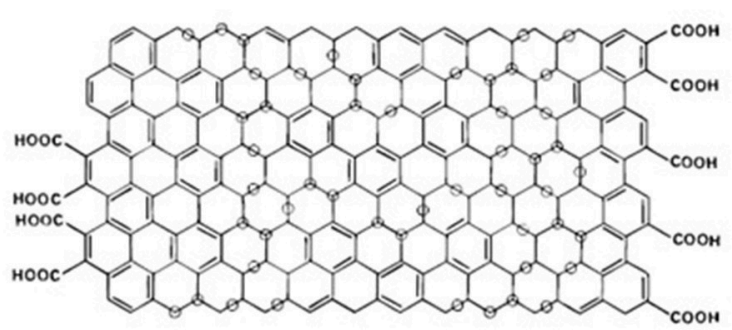

C
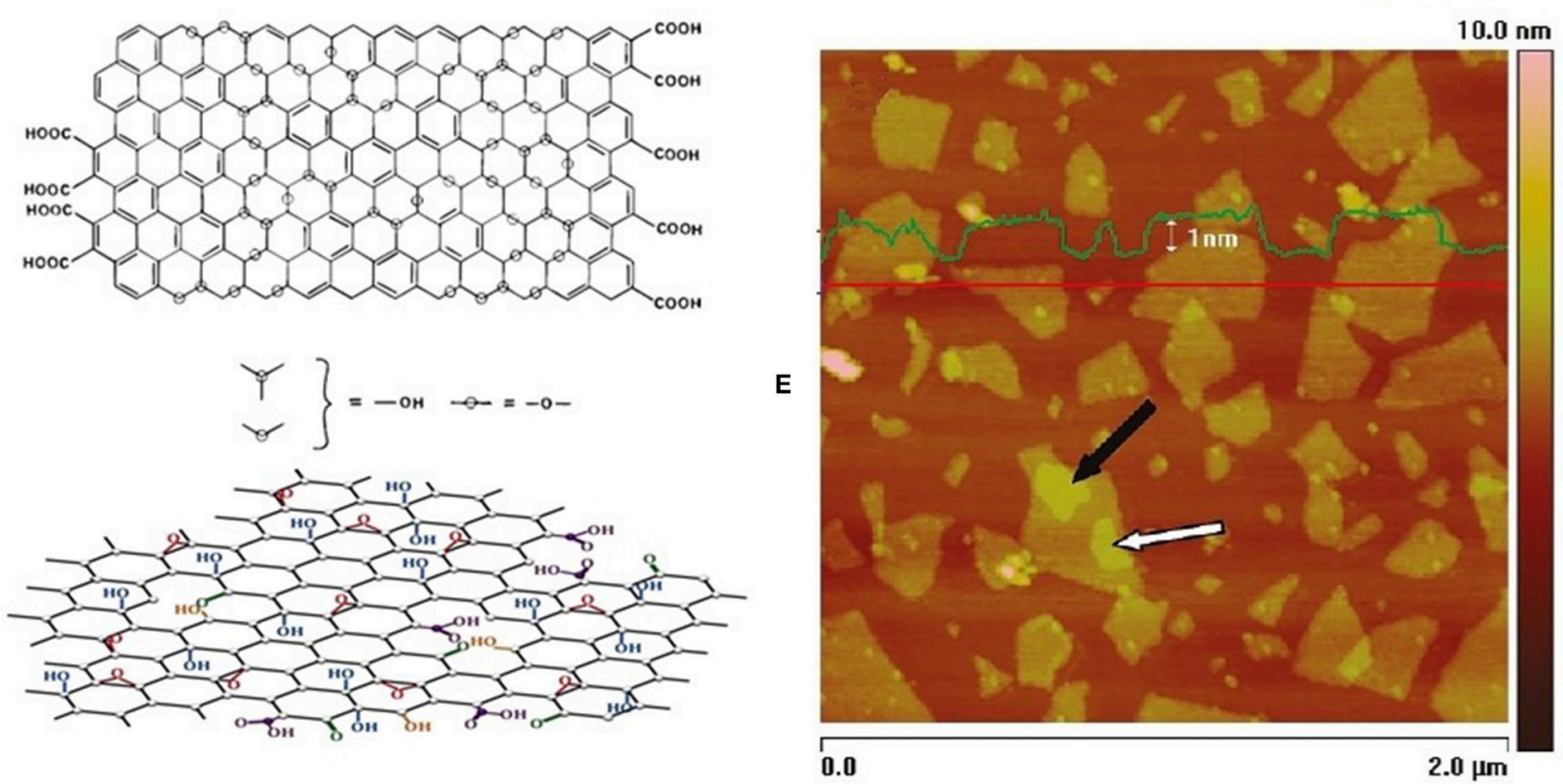

FIGURE 1 | Forms and structure of GO. (A) Aqueous dispersion of GO. Adopted with permission from Dong et al. [11] Copyright 2017ACS. Inc. (B) SEM image of large $\mathrm{GO}$ sheet on $\mathrm{Si} / \mathrm{SiO}_{2}$ substrate. Adopted with permission from Marcano et al. [9] Copyright ๑ 2010 ACS. (C) Scheme of GO structure accordingly to HRTEM data Ericson et al. [13] of single layer suspended sheet of GO. Pristine graphene regions are indicated by green hexagons, regions containing oxygen functionalities indicated in magenta and holes in basal plane marked by white approximate size is $8 \times 8$ nanometers. (D) Schematic structure of GO accordingly to Lerf-Klinovski model variations indicating ambiguity regarding the presence of carboxylic acids (top) or ester of tertiary alcohol, and ketone groups at the periphery of the basal plane (bottom), accordingly to Gao et al. [14]. Adopted with permission from Lerf et al. [15] Copyright @ 1998 ACS. (E) AFM image of GO particles on HOPG substrate. Superimposed profile of highs if taken along red line. Adopted with permission from Paredes et al. [16] Copyright $\odot 2009$ ACS.

Presence of graphene domains (Figure 2C) is the reason for noticeable broadband fluorescence in GO. Figure 2D demonstrates PL spectra of progressively reduced GO films. The total time of exposure to hydrazine noted in the legend. Excitation wavelength is $325 \mathrm{~nm}$. It reveals that the most intensive blue luminescence (Figure 2D) takes place in weakly reduced GO -about $3 \mathrm{~min}$ in hydrazine. The increase of grade of reduction gives dramatic quenching of light emission. Figure 2E shows the model for explanation of the observed effect. At top it demonstrates the results of calculation of band gap for the fragments of graphene with increase the size in structure of partially reduced GO. Scheme at bottom of Figure 2E demonstrates the transmission of excitation in structure of partially reduced GO between small graphene domains (large band gap) that absorb excitation light and large domains (small band gap) that emit PL photons. Thus the continuous spectrum of domain sizes is the reason for wideband PL and excitation spectra of partially reduced GO $[33,37]$.

Presence of hydroxyl and epoxy groups on the basal plane of sheets and carboxyl groups at their edges opens the way for chemical modification of as-prepared GO. Various methods of chemical modification of GO using activation of edge carboxyl groups discussed in review [34]. Using activation by thyonilchloryde $\left(\mathrm{SOCl}_{2}\right)$ and subsequent edition of amines or hydroxyls it is possible to obtain covalently attached various functional groups to GO particles. 


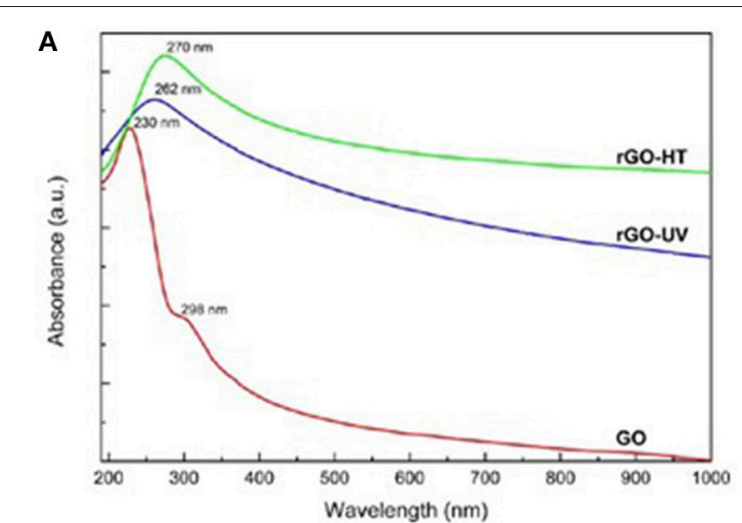

B

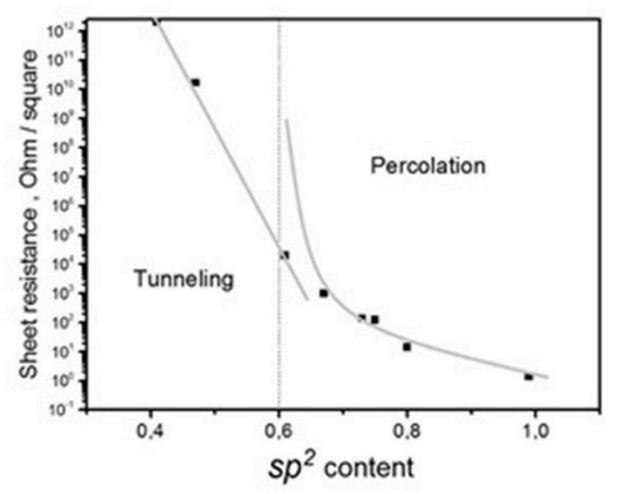

C

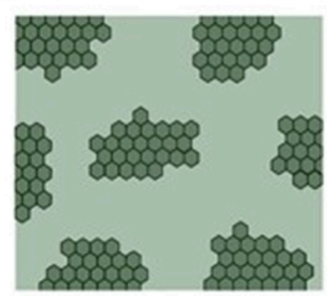

D

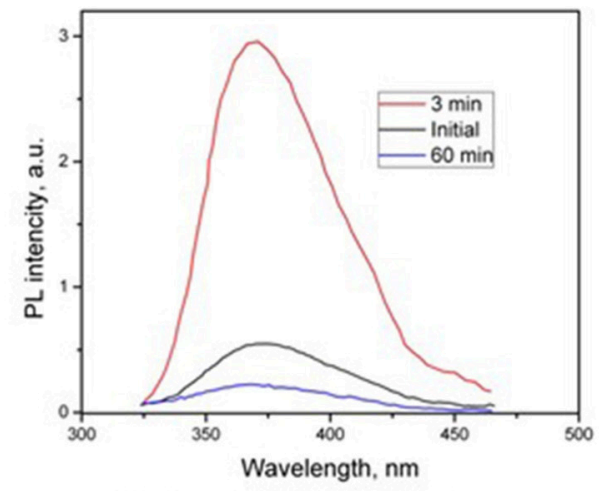

E

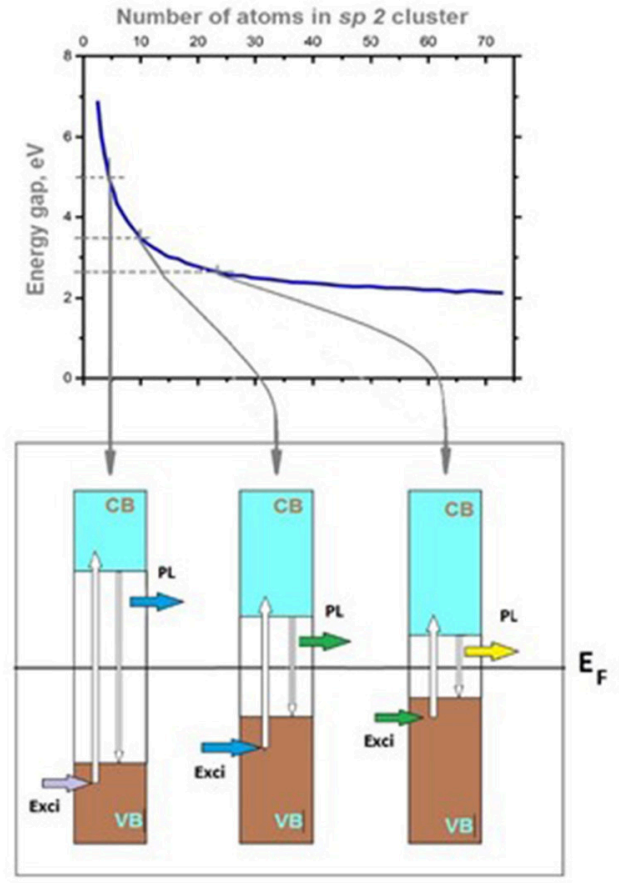

FIGURE 2 | Physical properties of GO. (A) Transformation of light absorption spectra of GO under thermal (rGO-HT) and UV reduction (rGO-UV). Adopted with permission from Kumar et al. [32] 2013 Nature. (B) Sheet resistance of thermally reduced GO vs. $s p^{2}$ carbon content. The vertical dashed line indicates the percolation threshold at $s p^{2}$ fraction of $\sim 0.6$. By data from Mattevi et al. [22]. (C) Schematic of evolution of GO domain structure at reduction: left-initial GO, right-partially reduced. In dark gray indicated $s p^{2}$ graphene regions, in light gray $-s p^{3}$ oxygen containing area. Accordingly to Mattevi et al. [22]. (D) PL luminescence spectra of progressively reduced GO films. The total time of exposure to hydrazine is noted in the legend. Excitation wavelength is $325 \mathrm{~nm}$. Data from from Eda et al. [33]. (E) Explanation of florescence of GO. At top: Estimated energy gap of $\pi-\pi^{\star}$ transitions as a function of the number atoms in graphene domain. At bottom: Schematic band structure of GO [blue and brown represent conduction (CB) and valence bands (VB), respectively]. Smaller sp ${ }^{2}$ domains have a larger energy gap due to a stronger confinement effect. Photogeneration of an electron-hole (e-h) pair on absorption of light (Exci) followed by relaxation and radiative recombination resulting in fluorescence $(\mathrm{PL})$ is depicted. White arrows denote the transitions of electrons and holes during this process. Accordingly to Eda et al. [33].

Scheme in Figure 3A demonstrates as example Isocyanate treatment of GO where organic isocyanates react with the hydroxyl (left oval) at basal plain of GO sheets giving attached carbamate functional groups. Right oval illustrates a reaction with carboxyl groups at the edges of GO platelets giving edge amide functionalization [38]. The approach for targeted covalent functionalization of epoxy groups at basal plane of GO sheets demonstrates Figure 3B. Use of amine-terminated ionic liquid (IL) [39] allows carrying out the ring opening nucleophilic reaction between epoxy groups and amine groups attached to ionic liquid. The reaction catalyzed by potassium hydroxide $(\mathrm{KOH})$ gives partially reduced GO modified by IL-NH 2 . It improves dispersibility of rGO in wide range of solvents. Similar functionalization of $\mathrm{GO}$ could be also carried out by ring-opening reactions with epoxy groups using octadecylamine. Conjugation of targeted functional groups gives opportunities for using GO platelets in various polymer composites [42], drug delivery systems [43], and biodevices [44]. 
A

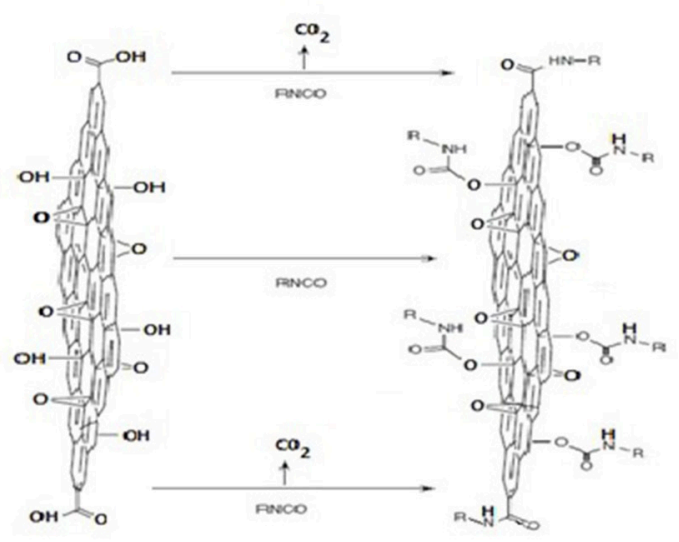

C
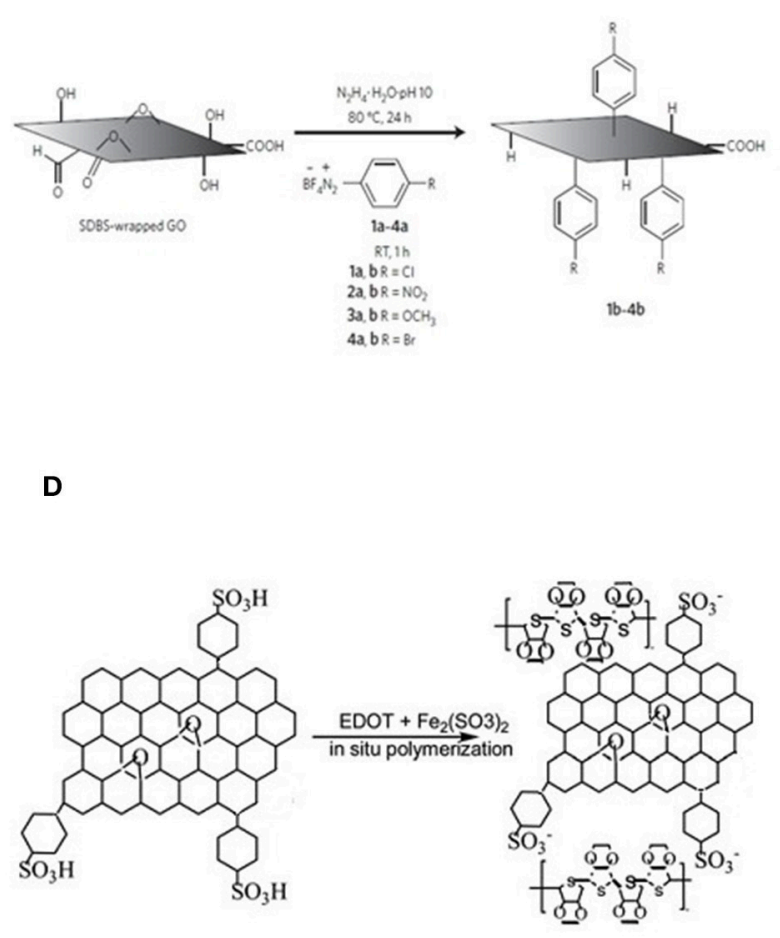

B

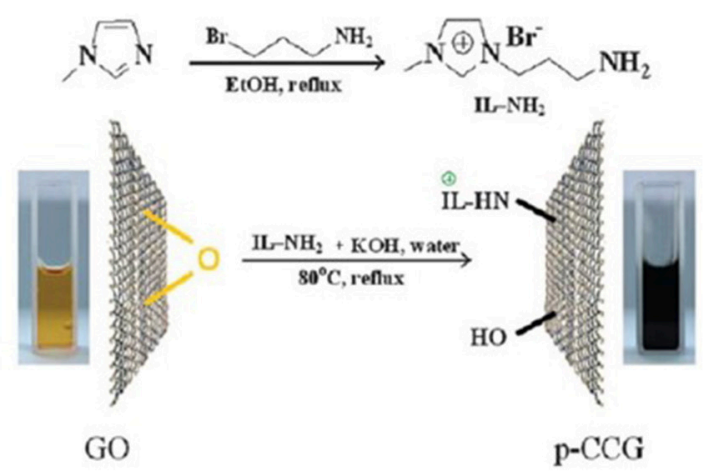

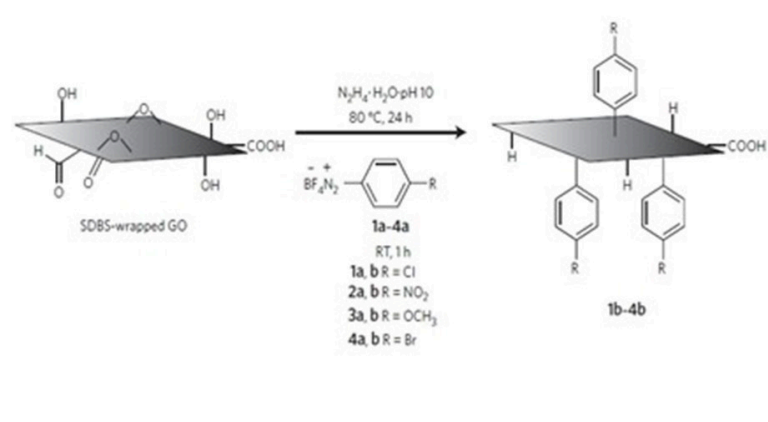

D

FIGURE 3 | Chemical modification of GO and rGO. (A) Isocyanate treatment of GO where organic isocyanates react with the hydroxyl (central arrow) and carboxyl groups (top and bottom arrows) of GO sheets to form carbamate and amide functionalities, respectively. Accordingly to Stankovich et al. [38] Copyright 2006, Elsevier, Inc. (B) Covalent functionalization of epoxy groups of GO by an ionic liquid. Adopted with permission from Yang et al. [39] Copyright 2009, RSC. (C) Diazonium functionalization of surfactant-wrapped chemically converted graphene sheets. GO was treated by sodium dodecylbenzenesulfonate (SDBS) surfactant. Adopted with permission from Lomeda et al. [40]. Copyright 2008 ACS. (D) Poly(3,4-ethyldioxythiophene)[PEDOT]/sulphonated graphene nanocomposite Accordingly to Xu et al. [41].

As was previously mentioned in Stankovich et al. [38] it could be useful to enhance solubility of GO sheets in organic solvents or reinforce polymer-GO composites in paper-like structures [45]. Presence of graphene $s p^{2}$ domains in structure of GO provides one more way for attachment the required functionality to the basal plane. Non-covalent functionalization (by cation $-\pi$ or van der Waals interaction) makes possible successful attachment of DNA or proteins to the surface of GO film for bio sensing [46].

\section{Reduction of GO}

At the beginning of the wave of interest GO was considered only as the way for mass production of cheap graphene. Therefore the most important task of transformation GO was in complete restoring structure and properties of graphene. Structure and chemical composition of GO at high level of oxidation are unstable. The significant part of oxygen containing functional groups can be easily removed from the basal plane of GO particle due to its high surface reactivity. The multiple research proposed broadest variety of methods for GO restoration $[8$, 47]. The existing methods of transformation $\mathrm{GO}$ to graphene could be nominally divided into three groups: physical (thermal), chemical and hybrid, where physical and chemical factors play role simultaneously.

The common feature of thermal methods is heating of GO directly or by irradiation [microwave, infrared visible, or ultraviolet (UV)] in vacuum, inert, or reducing atmosphere. Transformation of GO into rGO is going in wide range of temperatures. The obvious advantage of thermal reduction is simultaneous removal of oxygen-containing groups and restoring structure of $\mathrm{GO}$ by thermal annealing. It promotes the restoration of oxidation defects of GO basal plane afloat of sp3$\mathrm{sp} 2$ rehybridization of carbon atoms. Lower temperature limit for GO thermal reduction reported in Kumar et al. [32] is $50^{\circ} \mathrm{C}$. At that the reaching of its noticeable level requires several days. In case of GO films on substrate the upper limit of temperature depends mainly upon the substrate material, its thermal stability and chemical interaction with carbon at heating. In case of free membranes the upper level of temperature is limited by evaporation of carbon or destruction of graphene structure due to reaction with reducing atmosphere. Dong et al. [11] report the temperature of thermal reduction exceeding $2400^{\circ} \mathrm{C}$ obtained by direct Joule heating. This case the time required for full reduction of GO is less $1 \mathrm{~min}$. 
At the same time the typical range of temperature for thermal reduction is within $400-1200^{\circ} \mathrm{C}$. The choice is determined by reasonable duration of process for required grade of reduction GO. For this reason it is difficult to apply thermal reduction in liquid media or for GO films on organic and most inorganic substrates.

Chemical reduction uses various reactants. The frequently usable reagent for reduction of GO is hydrazine hydrate. Among well-known reactants that effectively restore GO to graphene are $\mathrm{Fe}$ powder, sodium borohydride, hydroquinone, hexamethylenetetramine, hydroiodic acid, sodium, and potassium alkaline solutions. It could be carried out in liquid media or vapor atmosphere at moderate or even at room temperature [47]. Catalyst assisted photoreduction methods could also be considered as chemical ones. For instance, presence of titanium dioxide particles effectively assist reduction of GO in aqueous media under UV irradiation [48]. Zinc oxide and bismuth vanadate also demonstrate photocatalyst properties for GO reduction in liquid media [47]. The additional advantage of chemical methods is in opportunity for simultaneous chemical modification of synthesizing material. Worth mentioning example of chemical approach is the group of environmental friendly soft reduction methods applying organic acids, sugars, protein amino acids, and even microorganisms [49]. The comparison of reduction of GO by chemical and thermal methods on obtained residual content of oxygen and sheet conductivity demonstrates the prominent advantage of thermal reduction [19].

The level of reduction achieved by chemical methods can be increased by using solvothermal method-combination of chemical and thermal treatment under supercritical conditions [50]. The similar hybrid approach allows to obtain the nitrogen doping of reduced GO $[51,52]$ with higher electric conductance. It was demonstrated the controllable perforation of ULGO platelets under soft UV irradiation in argon atmosphere. This method gives simultaneous modification of edges of holes by carboxyl groups useful for chemical sensor application [53]. Functionalization of rGO is based mostly on non-covalent wan der Waals and $\pi-\pi$ stacking interaction of polymers or small molecules with basal plane [36]. Unfortunately increasing concentration of defects of basal plane during oxidation as well as formation highly stable carbonyl and ether groups hinders the complete reduction of GO to graphene [26]. The detailed study has shown that during the reduction GO keeps substantially inhomogeneous structure of basal plane. Area that covered with $s p^{2}$ domains increases while oxygen containing $s p^{3}$ regions split into the isolated spots due to the energetically favorable diffusion of hydroxyl and epoxy groups [32]. At that a steep rise of conductance at some stage of reduction of GO corresponds to joining of $s p^{2}$ domains and overcoming the percolation threshold [22, 52].

Recent reviews suggest that due to incomplete restored structure of initial graphene and therefore to the smaller electrical conductance and electron mobility the reduced graphene oxide (rGO) will probably not substitute epitaxial CVD graphene in active electrical components [10]. At the same time many useful properties of rGO like controllable functionality, high electric and thermal conductance the availability of initial material, cheap and scalable preparation process make GO, and rGO the independent 2D carbon material with broadest variety of applications. For instance, rGO can be successfully functionalized by diazonium salts using preliminary treatment by sodium dodecylbenzenesulfonate (SDBS) surfactant [40] (Figure 3C). Sulphonated rGO can also be incorporated into polymer nanocomposite by co-polymerization with $\operatorname{Poly}(3,4-$ ethyldioxythiophene) [PEDOT] (Figure 3D) [41].

The results of intensive studies of properties and structure GO and rGO carried out at the beginning of this decade established a good base that is sufficient for start of developing the multitude of new technologies [54]. Therefore the research focus in the field of GO and rGO has prominently shifted to application area. The enormous number of research publications on applications of GO and rGO in various technological areas, exceeding 23,000 titles (according to WoS data) for 2 recent years demonstrates this fact.

\section{APPLICATIONS OF GRAPHENE OXIDE}

The critical property for significant part of applications of GO based materials is electric conductance. As it was mentioned above GO with high $\mathrm{O} / \mathrm{C}$ ratio is insulator. Therefore in order to increase the conductance of GO its partial restoration is required. That somewhat sacrifices chemical functionality of the material. Nevertheless, in number of applications mainly chemical and mechanical properties of GO are used. In this case it is important avoiding reduction process of $\mathrm{GO}$.

\section{Conductive Transparent Coatings}

Transparent protective and conductive coatings are one of the first and widely discussed applications for rGO [55-58]. Films with thickness of several atomic layers could be easily deposited on any hydrophilic surface by simple drop-casting method or spin coating [59] and subsequent evaporating water. In the case of using electrically conductive substrate the smoothness and density of the film can be enhanced by using electrophoresis [60]. If the surface of substrate is hydrophobic the dispersion in suitable organic solvent can be used. The reduction of GO films to rGO must be carried out avoiding damage of substrate. A suitable method, the most compatible to the substrate could be chosen from the broad variety of physical, chemical, or hybrid methods. The van der Waals adhesion to the substrate in most cases is sufficient for durable rGO films and coatings. It also could be enhanced using chemical bonding to carboxyl groups at the edges of rGO platelets that form a structure of the film. Using GO allows fabrication of transparent graphene electrodes of unrestricted area for displays, solar cells and luminescent light sources [61]. Graphene is less expensive and environmental friendly in comparison with traditional transparent conductor ITO and can successfully substitute it in most applications.

\section{Electronics}

rGO transparent films are somewhat less conductive then CVD graphene films fabricated by roll-to-roll technology [62] for the 
similar applications due to their tile-like structure [63]. At the same time the major advantage of rGO films is their better sustainability for deformation of substrate, which is important for application in flexible electronics. Selective transforming GO-rGO allows formation of electric interconnects on flexible substrates. Figure 4A illustrates the patterning process of GOrGO films on a flexible substrate under UV illumination A homogeneous dispersion of GO + N-Methyl-2-Pyrrolidone (NMP) spin coated and dried at $100 \mathrm{oC}$, before subjected to UV radiation for $45 \mathrm{~min}$ after masking with desired pattern [64]. Another attractive feature of GO is compatibility to ink-jet printing process $[68,69]$. It opens the wide area of applications in future electron devices including not only flexible and transparent circuit interconnections [70] but active elements like field effect transistors (FETs) [71, 72] and organic light emitting devices (OLEDs) [73, 74].

The conductance of rGO films with tile-like or paper-like structure determined mostly by contribution of contacts between
rGO sheets and less by their own resistance. Thus, development of technology for preparation of LGO and ULGO [12] will help to increase the conductance of transparent rGO electrodes. Correspondingly the additional chemical doping of GO also can help to increase conductance at moderate value of efficient mobility of charge carriers.

For some applications, the discontinuous structure of thin rGO film is critically important. Using rGO films as layers for transparent electrodes incorporated into GaN LED structure allows to increase the output power of LEDs avoiding the local overheating and damage of devices [75-77].

\section{Solar Cells}

Large area rGO transparent electrodes can become indispensable component of low cost flexible solar cells based on organic materials. Recently GO and chemically modified rGO were used as components for electron transport layers in new intensively developing organic perovskite based solar cells [78]. Using
A

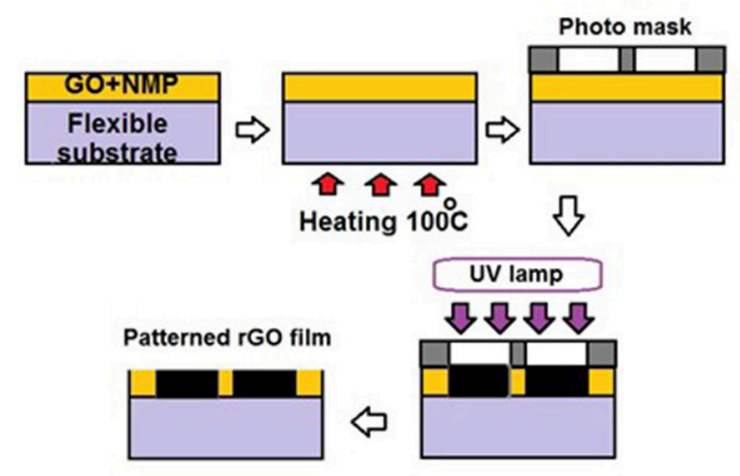

B

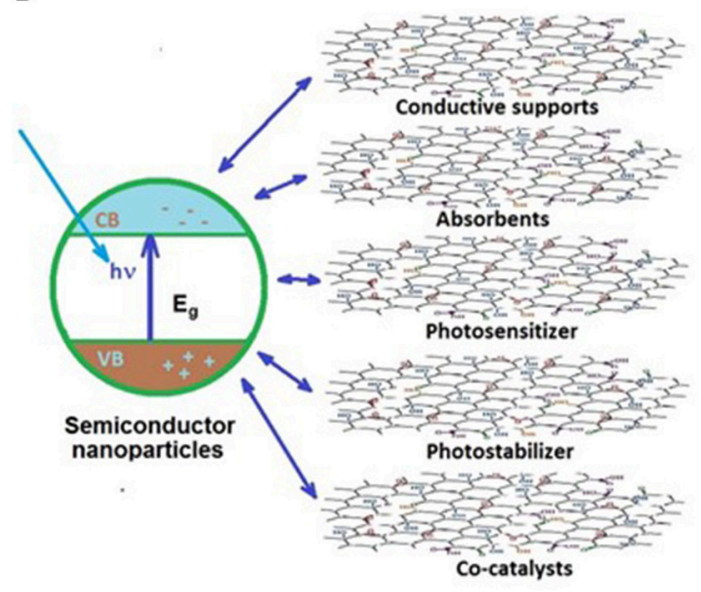

C

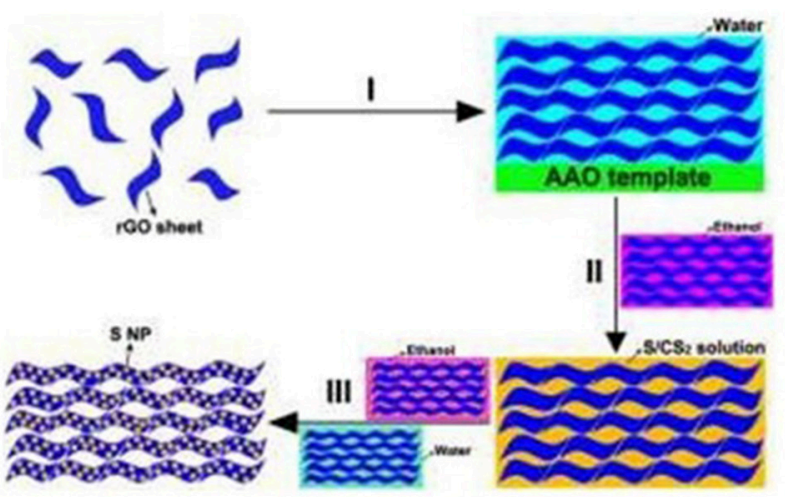

D

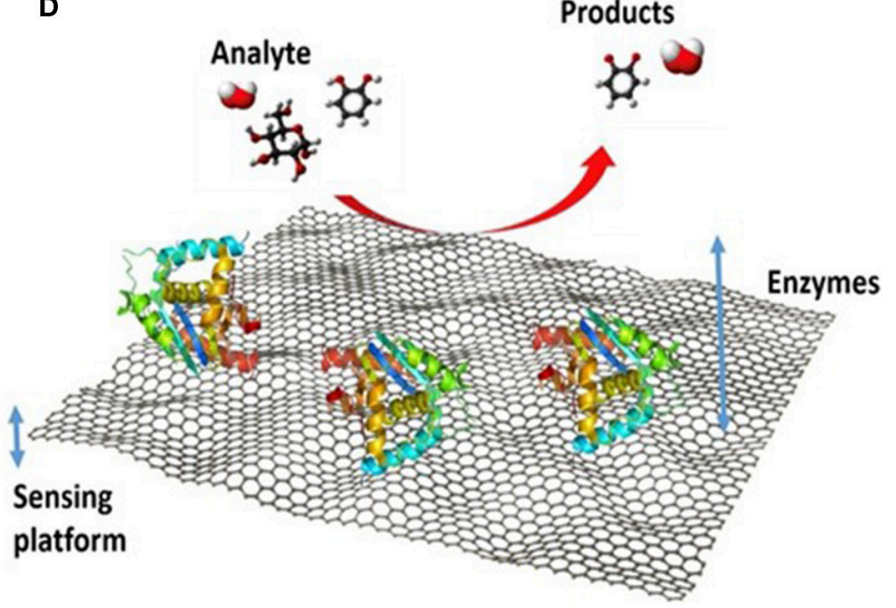

FIGURE 4 | Examples for applications of GO and rGO. (A) Schematic for patterning of GO-rGO films on a flexible substrate under UV illumination for applications in flexible electronics. Accordingly to Sonia et al. [64] Copyright 2018, Elsevier, Inc. (B) Functions of GO and rGO in graphene based composites for photocatalysts. Accordingly Li et al. [65]. Copyright $\odot 2016$ WILEY-VCH. (C) Schematic process of fabricating freestanding rGO-S composite films for cathodes of Li-S batteries. Adopted with permission from Luo et al. [66] Copyright 2017, RSC (D) Schematic of work process in enzymatic biosensor based of rGO platform. Adopted with permission from Bahamonde et al. [67]. Copyright The Author(s) 2018. 
GO and rGO results in noticeable enhancement of quantum efficiency and durability [79-82]. In Kakavelakis et al. [83] has been also demonstrated the effective method of synthesis of nanostructurized $\mathrm{TiO}_{2}$ (the important component of organic solar cells and photo catalysis systems) applying GO sheets as support and dispersant. GO or rGO are also useful materials for counter electrode in dye-sensitized ultralow cost solar cells based on liquid electrolyte [48].

\section{Photocatalysts}

Photocatalysis is one of the intensively developing and demanded technologies in particular for environmental protection [84]. Idea of photo catalyst may be considered as evolution of the organic solar cells concept. It combines solar energy conversion and carrying out the targeted electrochemical reaction. Photocatalysts use same nanoparticles of wide bandgap semiconductor like $\mathrm{TiO}_{2}$ or $\mathrm{ZnO}$ for solar light absorption and utilize the interface with aqueous electrolyte for charge separation of excited electron-hole pairs. It makes possible to carry out electrochemical oxidation of number of hazardous pollutions [84-88]. Incorporation of semiconductor nanocrystals into structure of nanocomposites with chemically modified GO and rGO allows spreading the range of available reactions [65]. Recently developed nanocomposite photocatalysts containing nanodots and transition metal nanoparticles open the way to dissociate even $\mathrm{H}_{2} \mathrm{O}$ and $\mathrm{CO}_{2}[65,89]$. $\mathrm{GO}$ and $\mathrm{rGO}$ in nanocomposite structure of photocatalyst act as binder, electrode and support for external chemical catalyst for carrying on the targeted reactions [85]. Recent publications also report the usage GO and rGO composites with nanoparticles of metals and other functionalization as effective conventional chemical catalyst for a variety of reactions [90-93] including synthesis of biofuel [94] The variety of functions of GO and rGO in nanocomposite graphene-based photocatalysts illustrates Figure 4B.

\section{Lithium Batteries}

Another focus of research interest in the field of GO and rGO is distinctly associated to electrodes for energy storage systemssupercapacitors and lithium batteries. Today lithium batteries possess maximum energy capacitance. Attention of researchers is attracted to improve anode materials for extension cycle life and electrochemical performance of conventional Li-ion rechargeable batteries [95-99]. At the same time the significant part of research efforts is attracted by Li-S batteries promising theoretical energy density almost order of magnitude higher then contemporary industrial samples [100].

Unfortunately, native sulfur used as cathode material in Li-S batteries brings obstacles on the way of industrial use. The main obstacle is the inherently low electrical conductivity of elemental sulfur used as cathode. Usage sulfur allotropes like S2-S4 chains renders number of technical obstacles including capacity fading and self-discharge. Moreover, the repeated dissolution and redeposition of sulfur results in rapid destruction of cathode. Therefore, the next step to industrial sulfur batteries requires the perfect host material for sulfur cathode. It must encapsulate elemental sulfur and simultaneously provide high electric conductance. According to the results of recent researches, it probably will be rGO and sulfur particles nanocomposite [99, 100]. Figure 4C demonstrates schematic process of fabricating freestanding rGO-S composite films by: I) self-assembling the rGO sheets by vacuum filtration to form solvated rGO films; II) immersing the solvated rGO films into the ethanol and subsequent S/CS2 (10 wt\% sulfur) solution to impregnate the sulfur into the interval space of solvated rGO films, III) washing the solvated rGO films with ethanol and water to purge the residual CS2 and ethanol, and freeze drying solvated rGO films with impregnation of sulfur to obtain the freestanding rGO-S composite films [66].

\section{Supercapacitors}

Although supercapacitors fall behind lithium batteries in energy capacity they are able to provide much greater peak power. It is important for variety of applications in industry, transport and communications. Supercapacitors store energy in electric double layer (EDLC) [101], formed by ions of liquid, solid or ionic liquid electrolyte accumulated on surface of electrode material. Therefore, the electrode material must be chemically inert, have the largest possible specific area and opened porous structure. It also must have smallest resistance and mechanical durability to provide maximum number of charge-discharge cycles at highest value of current.

rGO is a good candidate for electrode material for new generation of EDLC. The main issue having to overcome is instability of porous structure related to re-stacking of atomically thin rGO sheets $[101,102]$. The solution may be in making composite material of $\mathrm{GO}$ and conductive nanoparticles that form desirable porous structure and prevent stacking [103-105].

\section{Membranes}

The porous structure is of the same importance for GO membrane filters. Today membrane technologies of filtering wastewater and gases for separation heavy metals and $\mathrm{CO}_{2}$ play more and more significant role in environmental protection.

New results demonstrate successful application of membranes based on functionalized GO composites with polymers for effective separations of gas mixtures $\mathrm{CO}_{2} / \mathrm{CH}_{4}$ and $\mathrm{CO}_{2} / \mathrm{N}_{2}$ [106]. The ability of GO membranes for ionic and molecular sieving opens the way for separation of radiochemical wastes [107]. It was also reported that among the graphene-based materials, GO shows the best antimicrobial activity [108]. It was also demonstrated that interlayer spacing of GO based filtering membranes can be tuned trough intercalation by cations [109].

\section{Adsorbents}

Besides membranes chemically modified GO and GO based composites are effective adsorbents for removal various pollutions from wastewater [110] including heavy metal ions [111-113]. Moreover the GO based sorbents can be successfully regenerated for subsequent use [114, 115].

\section{Medicine and Biology}

The abilities for chemical modification in combination with its low cytotoxicity [116] provide GO broad opportunities for biological and medical applications. Late publications report 
using chemically modified GO as drag carrier for cancer therapy [117] and tool for gene cancer therapy based on ribonucleic acid (RNA) interference [118]. The combination of GO with quantum dots of AgInZnS produces tunable photoluminescence and can be used for in vivo optical imaging of cancer cells and for phototheraphy [119].

\section{Sensors for Chemistry and Biology}

The controllable resistivity of partially reduced GO films and good ability for chemical functionalization is the key property for making chemical and biological sensors for broad range of applications [120]. Due to the sharp dependence of resistivity of a few layer GO films from quantity and composition of chemical agents on its surface the sensor design can be very simple. Usually it consists of the film and a couple of metallic contacts. In order to enhance sensitivity more complicated FET structure can be constructed [121]. For selective sensitivity the surface can be modified by catalyst particles or chemical agents to enhance charge transfer from detecting agent to GO layer. It was successfully demonstrated GO is good sensor for hydrogen [122], nitrogen dioxide [123], humidity [124, 125].

Ultrasensitive sensor for environmental monitoring of bisphenols was fabricated with using gold nanoparticles/bcyclodextrin functionalized reduced graphene oxide nanocomposite as response element [126, 127]. Using a novel $\mathrm{Ni}(\mathrm{OH})(2) @ P E D O T-r G O$ nanocomposite ultrafast responsive and high sensitive electrochemical glucose sensor was successfully fabricated [128]. Also worth mentioning a beautiful colorimetric $\mathrm{pH}$ sensor based on responsive polymerquantum dot integrated graphene oxide [129]. Using enzyme reactions is a new approach for selectivity bio and chemical sensors. The basic principle of how enzymatic biosensors work is presented in Figure 4D [67]. Sensors employing enzymes can detect a variety of compounds with high specificity that would otherwise be difficult to detect in complex mixtures. For example, these sensors can be particularly useful in detecting compounds such as phenols, hydrogen peroxide, 17?-estradiol, glucose, and bilirubin. Obviously the variety of chemical sensors is growing year by year due to unrestricted opportunities for chemical modification of GO and ability for incorporation into nanocomposites.

\section{Microwave Absorbers}

One more noticeable branch of GO and rGO contemporary applications are microwave absorbers for electromagnetic interference (EMI) environmental protection. For microwave absorption aerogels of sponges [130] of GO and rGO are used. Results demonstrate 3D composites with carbon nanotubes/zinc ferrite [131], $\mathrm{ZnO}$ [132], and with nanosheets of $\mathrm{Co}_{3} \mathrm{O}_{4}$ [133].

\section{CONCLUSIONS AND OUTLOOK}

Although GO (rGO) is the closest relative of graphene, owing to its unique properties it takes the own independent place in graphene family. This material has wide application area and promising future. On Figure 5 one can see the variety of

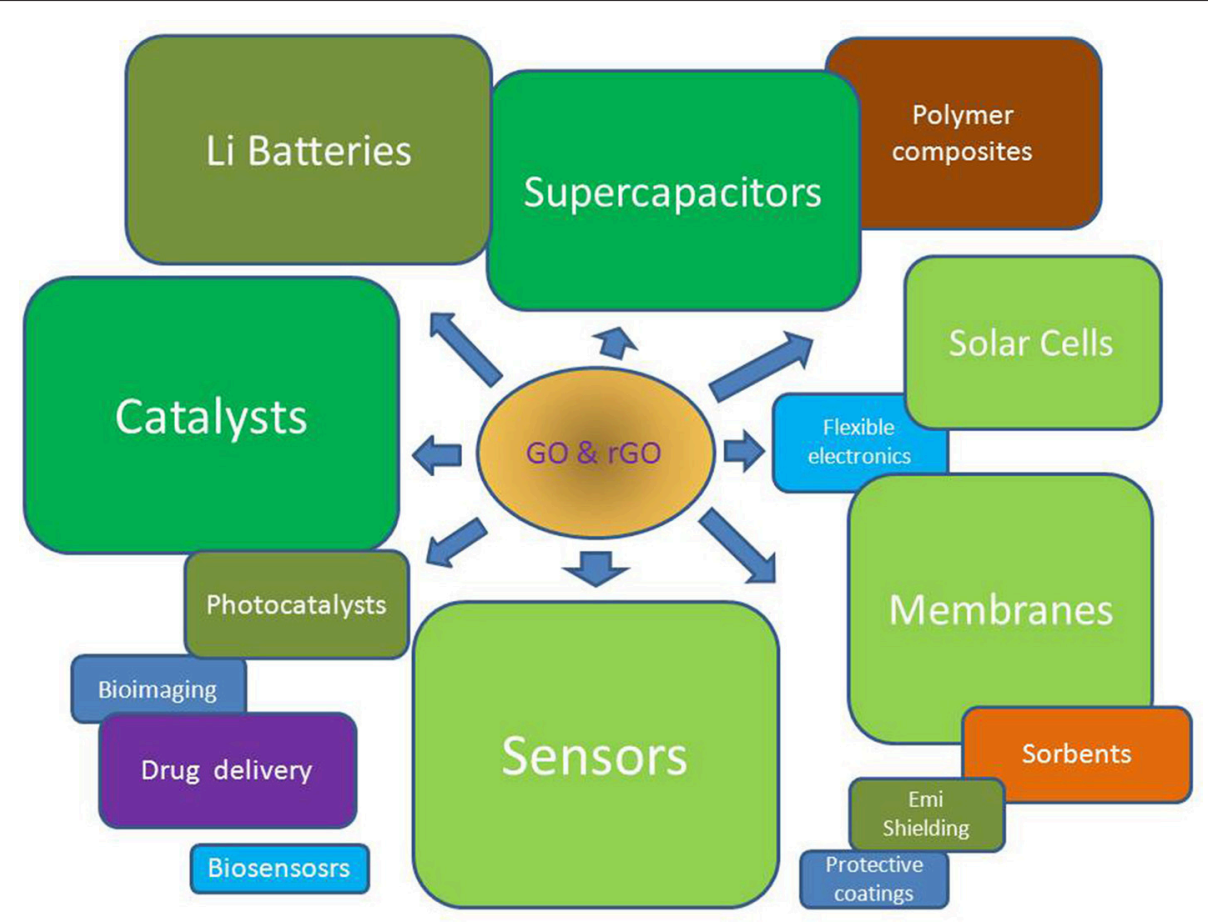

FIGURE 5 | Contemporary and prospective applications of GO and rGO. Size of blocks gives estimation of number of research publications for 2 recent years in corresponding areas. According to the Web of Science. 
contemporary and prospective applications of GO and rGO. The brief review is unable to cover the full range of its properties and applications. Its task is in revealing the most promising directions and to focus the efforts of researchers in the field of GO. Undoubtedly, in recent years research focus has shifted to applications of GO and its derivatives. The most promising demanded and supported directions are lying in the area of energy harvesting and storage, environmental protection, biology, and medicine. As it was demonstrated above in the mentioned fields, GO research is most successful and fruitful. However, despite of the good understanding of structure and main properties of GO some questions on basics of reversible transformation of graphene plane to its oxidized state are still waiting the answers.

The important remain problem of a detailed understanding the restoration process of the regular graphene structure at the edges of domains through $s p^{3}-s p^{2}$ re-hybridization during

\section{REFERENCES}

1. Park S, Ruoff RS. Chemical methods for the production of graphenes. Nat Nanotechnol. (2010) 5:217-24. doi: 10.1038/nnano.2010.69

2. Chen D, Feng H, Li J. Graphene oxide: preparation, functionalization, and electrochemical applications. Chem Rev. (2012) 112:6027-53. doi: $10.1021 / \mathrm{cr} 300115 \mathrm{~g}$

3. Tang L, Li X, Ji X, Teng KS, Tai G, Ye J, et al. Bottom-up synthesis of large-scale graphene oxide nanosheets. J Mater Chem. (2012) 22:5676-83. doi: 10.1039/c2jm15944a

4. Liu Y, Chen Y. Synthesis of large scale graphene oxide using plasma enhanced chemical vapor deposition method and its application in humidity sensing. $J$ Appl Physics (2016) 119:103301. doi: 10.1063/1.4942999

5. Bianco A, Cheng H-M, Enoki T, Gogotsi Y, Hurt RH, Koratkar N, et al. All in the graphene family -A recommended nomenclature for two-dimensional carbon materials. Carbon (2013) 65:1-6. doi: 10.1016/j.carbon.2013.08.038

6. Geim AK. Graphene prehistory. Phys Scr. (2012) T146:014003. doi: 10.1088/0031-8949/2012/T146/014003

7. Geim AK, Novoselov, KS. The rise of graphene. Nat Mater. (2007) 6:183-91. doi: 10.1038/nmat1849

8. Chen W, Yan L, Bangal PR. Preparation of graphene by the rapid and mild thermal reduction of graphene oxide induced by microwaves. Carbon (2010) 48:1146-52. doi: 10.1016/j.carbon.2009.11.037

9. Marcano DC, Kosynkin DV, Berlin JM, Sinitskii A, Sun Z, Slesarev A, et.al. Improved synthesis of graphene oxide. ACS Nano (2010) 4:4806-14. doi: $10.1021 / \mathrm{nn} 1006368$

10. Singh RK, Kumar R, Sing DP. Graphene oxide: strategies for synthesis, reduction and frontier applications. RSC Adv. (2016) 6:64993. doi: 10.1039/C6RA07626B

11. Dong L, Yang J, Chhowalla M, Loh KP. Synthesis and reduction of large sized graphene oxide sheets. Chem Soc Rev. (2017) 46:7306-16. doi: 10.1039/C7CS00485K

12. Lin S, Dong L, Zhang J, Lu H. Room-temperature intercalation and $\sim 1000$ fold chemical expansion for scalable preparation of high-quality graphene. Chem Mater. (2016) 28:2138-46. doi: 10.1021/acs.chemmater.5b05043

13. Erickson K, Erni R, Lee Z, Alem N, Gannett W, Zettl A. Determination of the local chemical structure of graphene oxide and reduced graphene oxide. Adv Mater. (2010) 22:4467-72. doi: 10.1002/adma.201000732

14. Gao W, Alemany LB, Ci L, Ajayan P M. New insights into the structure and reduction of graphite oxide. Nat Chem. (2009) 1:403-8. doi: $10.1038 /$ nchem.281

15. Lerf A, He H, Forster M, Klinowski J. Structure of graphite oxide revisited. J Phys Chem B (1998) 102:4477-82. doi: 10.1021/jp9731821 reduction of GO. It probably could help to solve the problem of the defects of graphene plane. It also could help to proximate developing the effective chemical method for preparation of perfect single layer graphene with unrestricted area.

It will extend the area of applications and open the modern industry for graphene technologies.

\section{AUTHOR CONTRIBUTIONS}

$\mathrm{AD}$ and $\mathrm{AV}$ both carefully outlined the contents of the review and wrote the entire manuscript.

\section{ACKNOWLEDGMENTS}

The research was supported by the Russian Foundation for Basic Research (Project N 18-29-19159). The authors thank M. K. Rabchinskii for useful discussions.

16. Paredes JI, Villar-Rodil S, Solis-Fernandez P, Martinez-Alonso A, Tascon JMD. Atomic force and scanning tunneling microscopy imaging of graphene nanosheets derived from graphite oxide. Langmuir (2009) 25:5957-68. doi: $10.1021 / \mathrm{la} 804216 \mathrm{z}$

17. Dong L, Chen ZX, Lin S, Wang K, Ma C, Lu HB. Reactivity-controlled preparation of ultralarge graphene oxide by chemical expansion of graphite. Chem Mater. (2017) 29:564-72. doi: 10.1021/acs.chemmater.6b03748

18. Cai W, Piner RD, Stadermann FJ, Park S, Shaibat MA, Ishii Y, et al. Synthesis and solid-state NMR structural characterization of 13C-labeled graphite oxide. Science (2008) 321:1815-17. doi: 10.1126/science.1162369

19. Casabianca LB, Shaibat MA, Cai WW, Park S, Piner R, Ruoff RS, et al. NMRbased structural modeling of graphite oxide using multidimensional 13C solid-state NMR and $a b$ initio chemical shift calculations. J Am Chem Soc. (2010) 132:5672-76. doi: 10.1021/ja9030243

20. Ganguly A, Sharma S, Papakonstantinou P, Hamilton J. Probing the thermal deoxygenation of graphene oxide using high-resolution in situ X-ray-based spectroscopies. J Phys Chem C (2011) 115:17009-19. doi: 10.1021/jp203741y

21. Lee DW, De Los Santos LV, Seo JW, Felix LL, Bustamante A, Cole DJM, et al. The structure of graphite oxide: investigation of its surface chemical groups. J Phys Chem B (2010) 114:5723-28. doi: 10.1021/jp1002275

22. Mattevi C, Eda G, Agnoli S, Miller S, Mkhoyan KA, Celik O, et al. Evolution of electrical, chemical, and structural properties of transparent and conducting chemically derived graphene thin films. Adv Funct Mater. (2009) 19:2577-83. doi: 10.1002/adfm.200900166

23. Saxena S, Tyson TA, Negusse E. Invedtigation of the local structure of graphene oxide. J Phys Chem Lett. (2010) 1:3433-37. doi: 10.1021/jz1014339

24. Lee V, Whittaker L, Jaye C, Baroudi KM, Fischer DA, Banerjee S. Largearea chemically modified graphene films: electrophoretic deposition and characterization by soft X-ray absorption spectroscopy. Chem Mater. (2009) 21:3905-16. doi: 10.1021/cm901554p

25. Gandhiraman RP, Nordlund D, Javier C, Koehne JE, Chen B, Meyyappan M. X-ray absorption study of graphene oxide and transition metal oxide nanocomposites. J Phys Chem C (2014) 118:18706-12. doi: 10.1021/jp503941t

26. Bagri A, Mattevi C, Acik M, Chabal YJ, Chhowalla M, Shenoy VB. Structural evolution during the reduction of chemically derived graphene oxide. Nat Chem. (2010) 2:581-7. doi: 10.1038/nchem.686

27. Acik M, Lee G, Mattevi C, Pirkle A, Wallace RM, Chhowalla M, et al. The role of oxygen during thermal reduction of graphene oxide studied by infrared absorption spectroscopy. Phys Chem C (2011) 115:19761-81. doi: $10.1021 /$ jp2052618

28. Si Y, Samulski ET. Synthesis of water soluble graphene. Nano Lett. (2008) 8:1679-82. doi: 10.1021/nl080604h 
29. Kudin KN, Ozbas B, Schniepp HC, Prudhomme RK, Aksay IA, Car R. Raman spectra of graphite oxide and functionalized graphene sheets. Nano Lett. (2008) 8:36-41. doi: 10.1021/nl071822y

30. Fujii S, Enoki T. Clar's aromatic sextet and $\mathrm{p}$-electron distribution in nanographene. Angew Chem Int Ed. (2012) 51:7236-41. doi: 10.1002/anie.201202560

31. Mkhoyan KA, Contryman AW, Silcox JD, Stewart A, Eda G, Mattevi C, et al. Atomic and electronic structure of graphene-oxide. Nano Lett. (2009) 9:1058-63. doi: 10.1021/nl8034256

32. Kumar PV, Bardhan NM, Tongay S, Wu J, Belcher AM, Grossman JC. Scalable enhancement of graphene oxide properties by thermally driven phase transformation. Nat Chem. (2014) 6:151-8. doi: 10.1038/nchem. 1820

33. Eda G, Lin Y-Y, Mattevi C, Yamaguchi H, Chen H-A, Chen I-S, et al. Blue photoluminescence from chemically derived graphene oxide. Adv Mater. (2009) 21:1-5. doi: 10.1002/adma.200901996

34. Dreyer DR, Park S, Bielawski CW, Ruoff RS. The chemistry of graphene oxide. Chem Soc Rev. (2010) 39:228-40. doi: 10.1039/B917103G

35. Neklyudov VV, Khafizov NR, Sedov IA, Dimiev AM. New insights into the solubility of graphene oxide in water and alcohols. Phys Chem Chem Phys. (2017) 19:17000-8. doi: 10.1039/C7CP02303K

36. Kravets VG, Marshall OP, Nair RR, Thackray B, Zhukov A, Leng J, et al. Engineering optical properties of a graphene oxide metamaterial assembled in microfluidic channels. Opt Express (2015) 23:1266-75. doi: 10.1364/OE.23.001265

37. Loh KP, Bao Q, Eda G, Chhowalla M. Graphene oxide as a chemically tunable platform for optical applications. Nat Chem. (2010) 2:1015-24. doi: $10.1038 /$ nchem. 907

38. Stankovich S, Piner RD, Nguyen ST, Ruoff RS, Synthesis and exfoliation of isocyanate-treated graphene oxide nanoplatelets. Carbon (2006) 44:3342-47. doi: 10.1016/j.carbon.2006.06.004

39. Yang HF, Shan CS, Li FH, Han DX, Zhang QX, Niu L. Covalent functionalization of polydisperse chemically-converted graphene sheets with amine-terminated ionic liquid. Chem Commun. (2009) 45:3880-2. doi: 10.1039/b905085j

40. Lomeda JR, Doyle CD, Kosynkin DV, Hwang W-F, Tour JM. Diazonium functionalization of surfactant-wrapped chemically converted graphene sheets. J Am Chem Soc. (2008) 130:16201-6. doi: 10.1021/ja806499w

41. Xu Y, Wang Y, Liang J, Huang Y, Ma Y, Wan X, et al. A hybrid material of graphene and poly (3,4-ethyldioxythiophene) with high conductivity, flexibility, and transparency. Nano Res. (2009) 2:343-8. doi: 10.1007/s12274-009-9032-9

42. Liang J, Xu Y, Huang Y, Zhang L, Wang Y, Ma Y, et al. Infrared-triggered actuators from graphene-based nanocomposites. J Phys Chem C (2009) 113:9921-7. doi: 10.1021/jp901284d

43. Weaver CL, LaRosa JM, Luo X, Cui XT. Electrically controlled drug delivery from graphene oxide nanocomposite films. ACS Nano (2014) 8:1834-43. doi: $10.1021 / \mathrm{nn} 406223 \mathrm{e}$

44. Liu X, Aizen R, Freeman R, Yehezkeli O, Willner I. Multiplexed aptasensors and amplified DNA sensors using functionalized graphene oxide: application for logic gate operations. ACS Nano (2012) 6:3553-63. doi: $10.1021 / \mathrm{nn} 300598 \mathrm{q}$

45. Park SD, Dikin A, Nguyen ST, Ruoff RS. Graphene oxide sheets chemically cross-linked by polyallylamine. J Phys Chem C (2009) 113:15801-4. doi: 10.1021/jp907613s

46. Wu M, Kempaiah R, Huang P-JJ, Maheshwari V, Liu J. Adsorption and desorption of DNA on graphene oxide studied by fluorescently labeled oligonucleotides. Langmuir (2011) 27:2731-8. doi: 10.1021/la1037926

47. Pei S, Cheng H-M. The reduction of graphene oxide. Carbon (2012) 50:321028. doi: 10.1016/j.carbon.2011.11.010

48. Williams G, Seger B, Kamat PV. $\mathrm{TiO}_{2}$-graphene nanocomposites. UVassisted photocatalytic reduction of graphene oxide. ACS Nano (2008) 2:1487-91. doi: 10.1021/nn800251f

49. De Silva KKH, Huang H-H, Joshib RK, Yoshimura M. Chemical reduction of graphene oxide using green reductants. Carbon (2017) 119:190-9. doi: 10.1016/j.carbon.2017.04.025

50. Wang H, Robinson JT, Li X, Dai H. Solvothermal reduction of chemically exfoliated graphene sheets. J Am Chem Soc. (2009) 131:9910-1. doi: $10.1021 /$ ja $904251 \mathrm{p}$
51. Li X, Wang H, Robinson JT, Sanchez H, Diankov G, Dai H. Simultaneous nitrogen doping and reduction of graphene oxide. J Am Chem Soc. (2009) 131:15939-44. doi: 10.1021/ja907098f

52. Mohan VB, Brown R, Jayaraman K, Bhattacharyya D. Characterization of reduced graphene oxide: effects of reduction variables on electrical conductivity. Mat Sci Eng B (2015) 193:49-60. doi: 10.1016/j.mseb.2014.11.002

53. Rabchinskii MK, Shnitov VV, Dideikin AT, Aleksenskii AE, Vul 'SP, Baidakova MV, et al. Nanoscale perforation of graphene oxide during photoreduction process in the argon atmosphere. J Phys Chem C (2016) 120:28261-9. doi: 10.1021/acs.jpcc.6b08758

54. Tan C, Cao X, Wu X-J, He Q, Yang J, Zhang X, et.al. Recent advances in ultrathin two-dimensional nanomaterials. Chem Rev. (2017) 117:6225-31. doi: 10.1021 /acs.chemrev.6b00558

55. Novoselov KS, Fal'ko VI, Colombo L, Gellert PR, Schwab MG, Kim K. A roadmap for graphene. Nature (2012) 490:192-200. doi: 10.1038/nature11458

56. Wu SX, Yin ZY, He QY, Huang X, Zhou XZ, Zhang H. Electrochemical deposition of semiconductor oxides on reduced graphene oxide-based flexible, transparent and conductive electrodes. (2010) J Phys Chem C. 114:11816. doi: 10.1021/jp103696u

57. Eda G, Fanchini G, Chhowalla M. Large-area ultrathin films of reduced graphene oxide as a transparent and flexible electronic material. Nat Nanotech. (2008) 3:270-4. doi: 10.1038/nnano.2008.83

58. Zhang X, Yan X, Chen J, Zhao J. Large-size graphene microsheets as a protective layer for transparent conductive silver nanowire film heaters. Carbon (2014) 69:437-43. doi: 10.1016/j.carbon.2013. 12.046

59. Yamaguchi H, Eda G, Mattevi C, Kim HK, Chhowalla M. Highly uniform $300 \mathrm{~mm}$ wafer-scale deposition of single and multilayered chemically derived graphene thin films. ACS Nano (2010) 4:524-8. doi: 10.1021/nn901496p

60. Lia S, Zhang Q, Lu Y, Ji D, Zhang D, Wu J, et al. One step electrochemical deposition and reduction of graphene oxide on screen printed electrodes for impedance detection of glucose. Sens Actuators B (2017) 244:290-8. doi: 10.1016/j.snb.2016.12.142

61. Morales-Masis M, De Wolf S, Woods-Robinson R, Ager JW, Ballif C. Transparent electrodes for efficient optoelectronics. Adv Electron Mater. (2017) 5:1600529. doi: 10.1002/aelm.201600529

62. Bae S, Kim H, Lee Y, Xu X, Park J-S, Zheng Y, et al. Roll-to-roll production of 30-inch graphene films for transparent electrodes. Nat Nanotechnol. (2010) 5:574-8. doi: 10.1038/nnano.2010.132

63. Zhao J, Pei S, Ren W, Gao L, Cheng H-M. Efficient preparation of large-area. Graphene oxide sheets for transparent conductive films. ACS Nano (2010) 4:5245-52. doi: 10.1021/nn1015506

64. Sonia M, Kumar P, Pandey J, Sharma SK, Soni A. Scalable and site specific functionalization of reduced graphene oxide for circuit elements and flexible electronics. Carbon (2018) 128:172-8. doi: 10.1016/j.carbon.2017.11.087

65. Li X, Yu J, Wageh S, Al-Ghamdi AA, Xie J. Graphene in photocatalysis: a review. Small (2016) 12:6640-96. doi: 10.1002/smll.201600382

66. Luo S, Yao M, Lei S, Yan P, Wei X, Wang X, et al. Freestanding reduced graphene oxide-sulfur composite films for highly stable lithium-sulfur batteries. Nanoscale (2017) 9:4646-51. doi: 10.1039/C7NR 00999B

67. Bahamonde J-P, Nguyen HN, Fanourakis SK, Rodrigues DF. Recent advances in graphene-based biosensor technology with applications in life sciences. $J$ Nanobiotechnol. (2018) 16:75. doi: 10.1186/s12951-018-0400-z

68. Gao M, Li L, Song Y. Inkjet printing wearable electronic devices. J Mater Chem C (2017) 5:2971-93. doi: 10.1039/C7TC00038C

69. Rogala M, Wlasny I, Dabrowski P, Kowalczyk PJ, Busiakiewicz A, Kozlowski $\mathrm{W}$, et al. Graphene oxide overprints for flexible and transparent electronics. Appl Phys Lett. (2015) 106:041901. doi: 10.1063/1.4906593

70. Oh J, Yoon HS, Kim WK, Kim SJ, Lee SC, Jung Y, et al. Flexible radio frequency interconnect of reduced graphene oxide. $2 D$ Materials (2018) 5:035030. doi: 10.1088/2053-1583/aab921

71. Eda G, Nathan A, Wöbkenberg P, Colleaux F, Ghaffarzadeh K, Anthopoulos $\mathrm{TD}$, et al. Graphene oxide gate dielectric for graphene-based monolithic field effect transistors. Appl Phys Lett. (2013) 102:133108. doi: 10.1063/1.47 99970 
72. Trung TQ, Tien NT, Kim D, Jang M, Yoon OJ, Lee N-E. A flexible reduced graphene oxide field-effect transistor for ultrasensitive strain sensing. $A d v$ Funct Mater. (2014) 24:117-24. doi: 10.1002/adfm.201301845

73. Yang Y, Yang X, Yang W, Li S, Xu J, Jiang Y. Ordered and ultrathin reduced graphene oxide LB films as hole injection layers for organic lightemitting diode. Nanoscale Res Lett. (2014) 9:537. doi: 10.1186/1556-276X9-537

74. Jia S, Sun HD, Du JH, Zhang ZK, Zhang DD, Ma LP, et al. Graphene oxide/graphene vertical heterostructure electrodes for highly efficient and flexible organic light emitting diodes. Nanoscale (2016) 8:10714-23. doi: 10.1039/C6NR01649A

75. Kim YS, Joo K, Jerng S-K, Lee J, Moon D, Kim J, et al. Direct integration of polycrystalline graphene into light emitting diodes by plasma -assisted metalcatalyst-free synthesis. ACS Nano (2014) 8:2230-6. doi: 10.1021/nn405477f

76. Han N, Cuong TV, Han M, Ryu BD, Chandramohan S, Park JB, et al. Improved heat dissipation in gallium nitride light-emitting diodes with embedded graphene oxide pattern. Nat Commun. (2013) 4:1452. doi: $10.1038 /$ ncomms 2448

77. Ryu BD, Han M, Han N, Park YJ, Ko KB, Lim TH, et al. Fabrication and characteristics of $\mathrm{GaN}$ based light emitting diodes with a reduced graphene oxide current spreading layer. ACS Appl Mater Interfaces (2014) 6:22451-6. doi: 10.1021/am506308t

78. Assadi MK, Bakhoda S, Saidur R, Hanaei H. Recent progress in perovskite solar cells. Renewable Sustain Ener Rev. (2018) 81:2812-22. doi: 10.1016/j.rser.2017.06.088

79. Dobrzanski LA, Prokopiuk M, Prokopowicz V, Drygała A, Wierzbicka A, Lukaszkowicz K, et al. Carbon nanomaterials application as a counter electrode for dye-sensitized solar cells. Arch Metall Mater. (2017) 62:27-32. doi: 10.1515/amm-2017-0004

80. Han GS, Song YH, Jin YU, Lee J-W, Park N-G, Kang BK, et al. Reduced graphene oxide/mesoporous $\mathrm{TiO} 2$ nanocomposite based perovskite solar cells. ACS Appl Mater Interfaces (2015) 7:23521-6. doi: 10.1021/acsami.5b06171

81. Arora N, Dar MI, Hinderhofer A, Pellet N, Schreiber F, Zakeeruddin $\mathrm{SM}$, et al. Perovskite solar cells with $\mathrm{CuSCN}$ hole extraction layers yield stabilized efficiencies greater than 20\%. Science (2017) 358:768-71. doi: 10.1126/science.aam5655

82. Yoon J, Sung H, Lee G, Cho W, Ahn N, Jung HS, et.al. Superflexible, high-efficiency perovskite solar cells utilizing graphene electrodes: towards future foldable power sources. Energy Environ Sci. (2017) 10:337-45. doi: 10.1039/C6EE02650H

83. Kakavelakis G, Maksudov T, Konios D, Paradisanos I, Kioseoglou G, Stratakis E, et al. Efficient and highly air stable planar inverted perovskite solar cells with reduced graphene oxide doped PCBM electron transporting layer. $A d v$. Energy Mater. (2017) 7:1602120. doi: 10.1002/aenm.201602120

84. Ong CB, Ng LY, Mohammad AW. A review of $\mathrm{ZnO}$ nanoparticles as solar photocatalysts: synthesis, mechanisms and applications. Renewable Sustain Energy Rev. (2018) 81:536-51. doi: 10.1016/j.rser.2017.08.020

85. Sudha D, Sivakumar P. Review on the photocatalytic activity of various composite catalysts. Chem Eng Process Process Intensification (2015) 97:11233. doi: 10.1016/j.cep.2015.08.006

86. Boyjoo Y, Sun H, Liu J, Pareek VK, Wang S. A review on photocatalysis for air treatment: from catalyst development to reactor design. Chem Eng J. (2017) 310:537-59. doi: 10.1016/j.cej.2016.06.090

87. Yang C, You X, Cheng J, Zheng H, Chen Y. A novel visible-light-driven in-based $\mathrm{MOF} /$ graphene oxide composite photocatalyst with enhanced photocatalytic activity toward the degradation of amoxicillin. Appl Catal B (2017) 200:673-80. doi: 10.1016/j.apcatb.2016.07.057

88. Deng F, Lu X, Pei X, Luo X, Luo S, Dionysioub DD. Fabrication of ternary reduced graphene oxide/SnS2/ZnFe2O4 composite for high visible-light photocatalytic activity and stability. J Hazardous Mater. (2017) 332:149-61. doi: 10.1016/j.jhazmat.2017.01.058

89. Lin L-Y, Nie Y, Kavadiya S, Soundappan T, Biswas P. N-doped reduced graphene oxide promoted nano $\mathrm{TiO} 2$ as a bifunctional adsorbent/photocatalyst for $\mathrm{CO} 2$ photoreduction: effect of $\mathrm{N}$ species. Chem Eng J. (2017) 316:449-60. doi: 10.1016/j.cej.2017.01.125

90. Chen Y, Yang X, Kitta M, Xu Q. Monodispersed Pt nanoparticles on reduced graphene oxide by a non-noble metal sacrificial approach for hydrolytic dehydrogenation of ammonia borane. Nano Res. (2017) 10:38116. doi: 10.1007/s12274-017-1593-4

91. Metin O, Can H, Sendil K, Gultekin MS, Monodisperse Ag/Pd core/shell nanoparticles assembled on reduced graphene oxide as highly efficient catalysts for the transfer hydrogenation of nitroarenes. J Colloid Interface Sci. (2017) 498:378-86. doi: 10.1016/j.jcis.2017.03.066

92. Lang B, Yu H-K. Novel Ag2S nanoparticles on reduced graphene oxide sheets as a super-efficient catalyst for the reduction of 4-nitrophenol. Chin Chem Lett. (2017) 28:417-21. doi: 10.1016/j.cclet.2016.10.019

93. Zarrinjahan A, Moghadam M, Mirkhani V, Tangestaninejad S, Mohammadpoor-Baltork I. Graphene oxide-bound electron-deficient tin(IV) porphyrin: a highly efficient and selective catalyst for trimethylsilylation of alcohols and phenols with hexamethyldisilazane. Appl Organometal Chem. (2017) 31:e3568. doi: 10.1002/aoc.3568

94. .Zheng X-C, Li N, Wu M, Guan X-X, Zhang X-L. Synthesis of biofuel via levulinic acid esterificationover porous solid acid consisting of tungstophosphoric acid and reduced graphene oxide. Res Chem Intermed. (2017) 43:6651-64. doi: 10.1007/s11164-017-3012-6

95. Chen B, Sha J, Li W, He F, Liu E, Shi C, et al. Graphene oxide-assisted synthesis of microsized ultrathin single-crystalline anatase $\mathrm{TiO} 2$ nanosheets and their application in dye-sensitized solar cells. ACS Appl Mater Interfaces (2016) 8:2495-504. doi: 10.1021/acsami.5b09058

96. Wang B, Jin J, Hong X, Gu S, Guo J, Wen Z. Facile synthesis of the sandwichstructured germanium/reduced graphene oxide hybrid: an advanced anode material for high-performance lithium ion batteries. J Mater Chem A (2017) 5:13430-38. doi: 10.1039/C7TA03087H

97. Li Z, Kong D, Zhou G, Wu S, Lv W, Luo C, et al. Twin-functional graphene oxide: compacting with $\mathrm{Fe} 2 \mathrm{O} 3$ into a high volumetric capacity anode for lithium ion battery. Energy Storage Mater. (2017) 6:98-103. doi: 10.1016/j.ensm.2016.09.005

98. Huang M, Feng M, Li H, Huang P, Su Q, Zhang F, et al. Rapid microwaveassisted synthesis of $\mathrm{SnO} 2$ quantum dots/reduced graphene oxide composite with its application in lithium-ion battery. Mater Lett. (2017) 209:260-3. doi: 10.1016/j.matlet.2017.08.006

99. Lv K, Zhang Y, Zhang D, Ren W, Sun L. Mn3O4 nanoparticles embedded in $3 \mathrm{D}$ reduced graphene oxide network as anode for high-performance lithium ion batteries. J Mater Sci Mater Electron. (2017) 28:14919-27. doi: $10.1007 / \mathrm{s} 10854-017-7413-5$

100. Peng H-J, Huang J-Q, Cheng X-B, Zhang Q. Review on high-loading and high-energy lithium-sulfur batteries. Adv Energy Mater. (2017) 7:1700260. doi: 10.1002/aenm.201700260

101. Wang F, Wu X, Yuan X, Liu Z, Zhang Y, Fu L, et al. Latest advances in supercapacitors: from new electrode materials to novel device designs. Chem Soc Rev. (2017) 46:6816-54. doi: 10.1039/C7CS00205J

102. Lukatskaya MR, Dunn B, Gogotsi Y. Multidimensional materials and device architectures for future hybrid energy storage. Nat Commun. (2016) 7:12647-59. doi: 10.1038/ncomms 12647

103. Naderi HR, Nasab AS, Nasrabadi MR, Ganjalia MR. Decoration of nitrogendoped reduced graphene oxide with cobalt tungstate nanoparticles for use in high-performance supercapacitors. Appl Surf Sci. (2017) 423:1025-34. doi: 10.1016/j.apsusc.2017.06.239

104. Wang F, Li G, Zhou Q, Zheng J, Yang C, Wang Q. One-step hydrothermal synthesis of sandwich-type NiCo2S4@reduced graphene oxide composite as active electrode material for supercapacitors. (2017) Appl Surf Sci. 425:180-7. doi: 10.1016/j.apsusc.2017.07.016

105. Zou X, Zhou Y, Wang Z, Chena S, Li W, Xiang B, et al. Free-standing, layered graphene monoliths for long-life supercapacitor. Chem Eng J. (2018) 350:386-94. doi: 10.1016/j.cej.2018.05.136

106. Vinoba M, Bhagiyalakshmi M, Alqaheem Y, Alomair AA, Pérez A, Rana MS. Recent progress of fillers in mixed matrix membranes for CO2 separation: a review. Sep Pur Technol. (2017) 188:431-50. doi: 10.1016/j.seppur.2017.07.051

107. Ma F, Li Z, Zhao H, Geng Y, Zhou W, Li Q, et al. Potential application of graphene oxide membranes for removal of $\mathrm{Cs}(\mathrm{I})$ and $\mathrm{Sr}$ (II) from high level-liquid waste Sep Pur Technol. (2017) 188:523-9.

108. Meng F, Zhang S, Oh Y, Zhou Z, Shin H-S, Chae S-R. Fouling in membrane bioreactors: an updated review Water Res. (2017) 114:151-80. doi: 10.1016/j.watres.2017.02.006 
109. Chen L, Shi G, Shen J, Peng B, Zhang B, Wang Y, et al. Ion sieving in graphene oxide membranes via cationic control of interlayer spacing. Nature (2017) 550:380-3. doi: 10.1038/nature24044

110. Wang S, Li X, Liu Y, Zhang C, Tan X, Zeng G, et al. Nitrogencontaining amino compounds functionalized graphene oxide: synthesis, characterization and application for the removal of pollutants from wastewater: a review. J Hazard Mater. (2018) 342:177-91. doi: 10.1016/j.jhazmat.2017.06.071

111. Peng W, Li H, Liu Y, Song S. A review on heavy metal ions adsorption from water by graphene oxide and its composites. J Mol Liq. (2017) 230:496-504. doi: 10.1016/j.molliq.2017.01.064

112. Sun Y, Wang X, Song W, Lu S, Chen C, Wang X. Mechanistic insights into the decontamination of Th(IV) on graphene oxide-based composites by EXAFS and modeling techniques. Environ Sci Nano (2017) 4:222-32. doi: 10.1039/C6EN00470A

113. Yu S, Wang J, Song S, Sun K, Li J, Wang X, et al. One-pot synthesis of graphene oxide and $\mathrm{Ni}-\mathrm{Al}$ layered double hydroxides nanocomposites for the efficient removal of U(VI) from wastewater. Sci China Chem. (2017) 60:415-22. doi: 10.1007/s11426-016-0420-8

114. Wang J, Li Y, Chen W, Peng J, Hu J, Chen Z, et al. The rapid coagulation of graphene oxide on La-doped layered double hydroxides. Chem Eng J. (2017) 309:445-53. doi: 10.1016/j.cej.2016.10.053

115. Qi Y, Yang M, Xu W, He S, Men Y. Natural polysaccharides-modified graphene oxide for adsorption of organic dyes from aqueous solutions. $J$ Colloid Interface Sci. (2017) 486:84-96. doi: 10.1016/j.jcis.2016.09.058

116. Zhang L-N, Deng H-H, Lin F-L, Xu X-W, Weng S-H, Liu A-L, et al. In situ growth of porous platinum nanoparticles on graphene oxide for colorimetric detection of cancer cells. Anal Chem. (2014) 86:2711-8. doi: $10.1021 / \mathrm{ac} 404104 \mathrm{j}$

117. Ma N, Liu J, He W, Li Z, Luan Y, Song Y, Garg S. Folic acid-grafted bovine serum albumin decorated graphene oxide: An efficient drug carrier for targeted cancer therapy. J Colloid Interface Sci. (2017) 490:598-607. doi: 10.1016/j.jcis.2016.11.097

118. Ren L, Zhang Y, Cui C, Bi Y, Ge X. Functionalized graphene oxide for antiVEGF siRNA delivery: preparation, characterization and evaluation in vitro and in vivo. RSC Adv. (2017) 7:20553-66. doi: 10.1039/C7RA00810D

119. Zang Z, Zeng X, Wang M, Hu W, Liu C, Tang X. Tunable photoluminescence of water-soluble AgInZnS-grapheneoxide (GO) nanocomposites and their application in-vivo bioimaging. Sens Actuators B (2017) 252:1179-86. doi: 10.1016/j.snb.2017.07.144

120. Justino CIL, Gomes AR, Freitas AC, Duarte AC, Rosha-Santos TAP. Graphene based sensors and biosensors. Trends Anal Chem. (2017) 91:53-66. doi: 10.1016/j.trac.2017.04.003

121. Yu C, Chang X, Liu J, Ding L, Peng J, Fang Y. Creation of reduced graphene oxide based field effect transistors and their utilization in the detection and discrimination of nucleoside triphosphates. ACS Appl Mater Interfaces (2015) 7:10718-26. doi: 10.1021/acsami.5b00155

122. Wang J, Rathi S, Singh B, Lee I, Joh H-I, Kim G-H. Alternating current dielectrophoresis optimization of Pt-decorated graphene oxide nanostructures for proficient hydrogen gas sensor. ACS Appl Mater Interfaces (2015) 7:13768-75. doi: 10.1021/acsami.5b01329
123. Lee SW, Lee W, Hong Y, Lee G, Yoon DS. Recent advances in carbon material-based NO2 gas sensors. Sens Actuators B (2018) 255:1788-804. doi: 10.1016/j.snb.2017.08.203

124. Yu H-W, Kim HK, Kim T, Bae KM, Seo SM, Kim J-M, et al. Self-powered humidity sensor based on graphene oxide composite film intercalated by poly(sodium 4-styrenesulfonate). ACS Appl Mater Interfaces (2014) 6:83206. doi: 10.1021/am501151v

125. Rathi K, Pal K. Impact of doping on GO: fast response-recovery humidity sensor. ACS Omega (2017) 2:842-51. doi: 10.1021/acsomega.6b 00399

126. Yun Y. Electrochemical sensor for ultrasensitive determination of bisphenol A based on gold nanoparticles/b-cyclodextrin functionalized reduced graphene oxide nanocomposite. Int J Electrochem Sci. (2016) 11:2778-89. doi: 10.20964/110402778

127. Dhanjai SA, Wu L, Lu X, Chen J, Jain R. Advances in sensing and biosensing of bisphenols: a review. Anal Chim Acta (2018) 998:1-27. doi: 10.1016/j.aca.2017.09.048

128. Sheng L, Li Z, Meng A, Xu Q. Ultrafast responsive and highly sensitive enzyme-free glucose sensor based on a novel $\mathrm{Ni}(\mathrm{OH})(2) @ P E D O T-$ rGO nanocomposite. Sens Actuators B (2018) 254:1206-15. doi: 10.1016/j.snb.2017.08.008

129. Paek K, Yang H, Lee J, Park J, Kim BJ. Efficient colorimetric pH sensor based on responsive polymer-quantum dot integrated graphene oxide. ACS Nano (2014) 8:2848-56. doi: 10.1021/nn406657b

130. Chabot V, Higgins D, Yu A, Xiao X, Chenand Z, Zhang J. A review of graphene and graphene oxide sponge:material synthesis and applications to energy and the environment. Energy Environ Sci. (2014) 7:1564-96. doi: $10.1039 / \mathrm{c} 3$ ee43385d

131. Shu R, Zhang G, Zhang J, Wang X, Wang M, Gan Y, et al. Fabrication of reduced graphene oxide/multi-walled carbon nanotubes/zinc ferrite hybrid composites as high-performance microwave absorbers. J Alloys Compd. (2018) 736:1-11. doi: 10.1016/j.jallcom.2017.11.084

132. Zheng YD, Luo ZB, Liao Q, Liu S, Liu Y, Zhang Y. Investigation on the broadband electromagnetic wave absorption properties and mechanism of Co3O4-nanosheets/reduced graphene- oxide composite. Nano Res. (2017) 10:980-90. doi: 10.1007/s12274-016-1357-6

133. Song C, Yin X, Han M, Li X, Hou Z, Zhang L, et al. Threedimensional reduced graphene oxide foam modified with $\mathrm{ZnO}$ nanowires for enhanced microwave absorption properties. Carbon (2017) 116:50-8. doi: 10.1016/j.carbon.2017.01.077

Conflict of Interest Statement: The authors declare that the research was conducted in the absence of any commercial or financial relationships that could be construed as a potential conflict of interest.

Copyright (c) 2019 Dideikin and Vul'. This is an open-access article distributed under the terms of the Creative Commons Attribution License (CC BY). The use, distribution or reproduction in other forums is permitted, provided the original author(s) and the copyright owner(s) are credited and that the original publication in this journal is cited, in accordance with accepted academic practice. No use, distribution or reproduction is permitted which does not comply with these terms. 